\title{
Made in China 2025 e Industrie 4.0 \\ A difícil transição chinesa do catching up à economia puxada
}

pela inovação ${ }^{1}$

\author{
Glauco Arbix*, Zil Miranda**, \\ Demétrio Toledo** e Eduardo Zancul*
}

Apresentação

As fortes mudanças tecnológicas iniciadas no final dos anos de 1970, e que foram alavancadas de modo extraordinário nos últimos vinte anos, estiveram na base do ritmo acelerado executado pela China nos processos de absorção e desenvolvimento de novas tecnologias. Com tratamento especial, Ciência, Tecnologia e Inovação (Ст\&I) foram compreendidas e adotadas como essenciais para o desenvolvimen-

'Universidade de São Paulo, São Paulo, Brasil.

${ }^{* *}$ Universidade Federal do ABC, Santo André, Brasil.

1. Artigo baseado em levantamentos realizados sobre China e Alemanha para o estudo "Inovação, Manufatura Avançada e o Futuro da Indústria”, financiado pela Agência Brasileira de Desenvolvimento Industrial (ABDI), executado pelo Centro Brasileiro de Análise e Planejamento (Cebrap), com supervisão técnica do Observatório da Inovação e Competitividade do Instituto de Estudos Avançados da USP. A análise sobre a política chinesa baseia-se em pesquisa bibliográfica sobre o tema, cotejada com entrevistas realizadas junto à Embaixada Brasileira na China, sendo os autores gratos ao então embaixador do Brasil na China, Roberto Jaguaribe, e ao ministro Romero Maia, da Embaixada em Pequim, pelas informações inéditas colhidas junto ao governo, centros de pesquisa e visitas às empresas chinesas. Já o levantamento e a avaliação da política alemã, Industrie 4.0, foram realizados a partir de visitas a empresas, laboratórios experimentais, universidades, institutos e associações situados em várias regiôes da Alemanha, muitas sugeridas pela Embaixada brasileira em Berlim. Entrevistas com o secretariado geral da plataforma, representantes do governo, lideranças empresariais, científicas e planejadores públicos permitiram a criteriosa reunião de documentos, dados e informações, realizada pelo professor da Escola Politécnica da USP Eduardo Zancul e por Guilherme Amaral, doutor pela Politécnica-usp. 
GRÁFICO 1

Dispêndio em Pß̛̃ em Relação ao PIB, Países Selecionados - 2000-2014

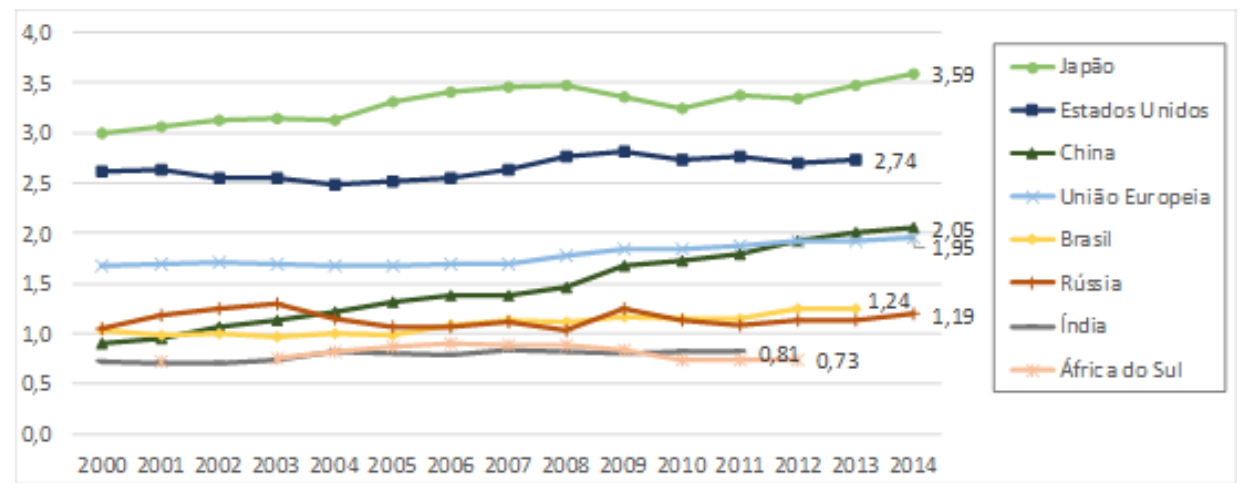

Fonte: OECD, 2016 (http://stats.oecd.org/\#). Dados acessados em 12 de março de 2018.

to econômico e designadas a ocupar posição de destaque nos grandes planos do governo chinês.

A evolução do investimento em pesquisa e desenvolvimento (P\&D), que saltou de menos de $1 \%$ do PIB no início dos anos 2000 para pouco mais de 2,0\% em 2014, surpreendeu pela dimensão e velocidade com que diferenciou a China dos demais países dos Brics: em período semelhante, e partindo de um patamar levemente mais alto, o Brasil chegou a 1,24\% (em 2013) e a Rússia a 1,19\%. Embora ainda não tenha atingido níveis semelhantes aos do Japão (3,59\%) e dos Estados Unidos (2,74\% em 2013), o dispêndio chinês em P\&D superou a média da União Europeia, de $1,95 \%$ do PIB $^{2}$.

Em sua trajetória marcada pelo esforço de catching up, o governo chinês procurou desenvolver a CT\&I com estilo decisório top down, fortemente enraizado nas instituições de Estado, característica que marca, direta ou indiretamente, todo o esforço chinês de upgrading tecnológico realizado desde a revolução de 1949 (Lee, 2013).

Porém, no patamar que a China já alcançou, com avanços significativos na geração de inovações, o desafio que se apresenta aos governantes e policy makers é o de massificar, sustentar e superar os processos de catching up, de modo a permitir o ingresso da China no seleto clube dos países que expandem a fronteira do conhecimento, dinamizam constantemente suas economias e conseguem, com isso, manter ou elevar o alto padrão de renda de suas populações (Liu et al., 2011). O nó da questão é que a história desde a Segunda Guerra Mundial ensina que poucos conseguiram realizar essa transição, a exemplo da Coreia do Sul, Singapura e Taiwan (e mesmo assim,

2. Ainda com dados do Reino Unido. 
parcialmente), o que exige estratégias, lideranças, políticas e instituições distintas daquelas que sustentaram a fase de catching up (Breznitz e Murphree, 2011).

O problema, portanto, de elaboração e execução de políticas públicas e de mobilização da sociedade, de modo a levar o país a superar de vez a dependência da produção de bens de baixo valor agregado e mostrar-se capaz de consolidar uma economia puxada pela inovação, assume importância de primeira ordem para a China (Eichengreen, Park e Shin, 2012).

Quais políticas? Com quais características? Com quais custos, econômicos e sociais? Com que padrão de eficácia?

Como contribuição para esse debate e a difícil construção de algumas respostas, este artigo se debruça sobre alguns dos principais planos estatais de inovação responsáveis pelos avanços chineses em CT\&I. Como será possível notar, chama atenção a preocupação do governo central com o planejamento de longo prazo, com a definição de metas e de ações que orientem todos os níveis de governo. Além disso, a percepção da necessidade de manter o compasso com as tendências internacionais levou o país a marcar posição nos processos de manufatura avançada, desenhando uma política voltada aos segmentos tecnológicos de ponta, a exemplo da Alemanha.

Mas, diferentemente da Alemanha, que construiu um sistema educacional em constante sinergia com o mundo das empresas e um ambiente regulatório amigável à inovação, na China, uma ampla camada de empresas, muitas médias e pequenas, conseguiu acesso ao mercado global a partir do desenvolvimento de inovações maduras (e não high tech), em meio a um ambiente que privilegia as grandes corporações e, na maior parte das vezes, sem suporte dos planos e programas estatais (Breznitz e Murphree, 2011; Breznitz, 2014). Apesar da incerteza que envolve o ambiente de CT\&I, essas empresas foram capazes de se conectarem a cadeias de alto valor e de contribuir para impulsionar o constante upgrading da capacidade endógena de desenvolvimento tecnológico e de inovação chinesa.

Em síntese, o presente artigo: (1) sistematiza as políticas públicas e diretrizes adotadas para elevar o patamar de CT\&I e a qualidade da economia chinesa; (2) acompanha a diversificação do sistema de inovação e a combinação dos planos e programas públicos com as estratégias das empresas em ambiente de incerteza; (3) compara as recentes políticas chinesa e alemã para a manufatura avançada; (4) identifica obstáculos e discute a estratégia chinesa de catching up; e (5) apresenta sugestões para o Brasil. 


\section{Avanços chineses}

A imagem da China como celeiro da indústria da cópia barata e da mão de obra abundante e pouco qualificada já não é um retrato fiel dessa nação de 9,5 milhões de $\mathrm{km}^{2}$ e quase 1,4 bilhão de habitantes. Atualmente, a China começa a disputar a liderança em tecnologias da informação e comunicação (as gigantes Huawei, Xiaomi e ZTE estão entre as maiores empresas do setor), trens de alta velocidade (China South Locomotive e Rolling Stock), energias renováveis (Trina Solar e Yingli Green Energy), energia solar e eólica (Goldwind, United Power e Ming Yang) e supercomputadores (com tecnologia 100\% chinesa, o TaihuLight, da empresa Sunway Systems, está no topo da lista de computadores mais rápidos do mundo). A formação desses grandes conglomerados acompanhou o surgimento de empresas em segmentos não tradicionais, como a Baidu (motor de busca na web, com forte investimento em inteligência artificial e veículos autônomos), a Tencent (criadora do WeChat), a Alibaba (e-commerce) e Didi (serviços tipo Uber) ${ }^{3}$.

A elevação do patamar produtivo da economia chinesa, propiciada pelo surgimento de novos segmentos, complexos industriais e proliferação de empresas inovadoras, insiste em desafiar análises econômicas as mais diversas.

A ascensão chinesa, juntamente com a evolução de um conjunto de outros países emergentes, modificou o mapa da produção mundial de bens e serviços a partir dos anos 2000 e mergulhou esses países em atividades de geração de conhecimento e inovações (Van Noorden, 2016; Zhou, Lazonick e Sun, 2016; Royal Society, 2011). A pró-atividade do Estado em várias frentes - incentivo às grandes empresas, reformas pró-mercado, qualificação da mão de obra, atração de capital externo - manteve, desde o início das reformas em 1979, a CT\&I como uma prioridade nacional, o que garantiu estabilidade do investimento público de médio e longo prazo.

Exemplo mais recente dessa priorização é a entrada da China nos projetos de big science, assim chamados por serem iniciativas de alto custo e enormes desafios científicos e tecnológicos, desenvolvidos sobretudo nos Estados Unidos e na Europa no pós-Segunda Guerra. A prevalência de equipamentos sofisticados, o grande número e, principalmente, a competência dos cientistas envolvidos com as iniciativas de big science abriram novos caminhos para a produção avançada de conhecimento no mundo todo ${ }^{4}$. A China, coerentemente com suas pretensões e a tradição de replicar

\footnotetext{
3. É importante registrar que, ao lado do mérito próprio, essas novas empresas de tecnologia se beneficiaram das restrições ao livre acesso aos sites das empresas ocidentais que dominam o mercado mundial impostas pelo The Great Chinese Firewall.

4. Exemplos: o projeto Manhattan, criado em 1939 (que gerou a bomba atômica), a criação da National Aeronautics and Space Administration (Nasa, de 1958), o Apollo Program, que colocou o homem
} 
experiências de vulto dos países avançados, passou a oferecer infraestrutura de última geração para que seus pesquisadores pudessem participar de projetos de big science e desenvolvê-los, como mostra o quadro a seguir.

QUADRO 1

China: Projetos (Selecionados) de Big Science

\begin{tabular}{ll}
\hline Centro de radiação Síncroton de Shanghai & Maior investimento em ciência até então realizado pela China (2009). \\
\hline Quantum Highway & $\begin{array}{l}\text { Maior rede de comunicação quântica do mundo, que conecta Beijing } \\
\text { e Shanghai. }\end{array}$ \\
\hline $\begin{array}{l}\text { Três centros de lançamento de satélites: } \\
\text { Jiuquan, Taiyuan e Xichang }\end{array}$ & $\begin{array}{l}\text { Jiuquan, o mais antigo, lançou em 2015 a primeira missão espacial. } \\
\text { Xichang, o mais recente, para lançamento de satélites geoestacionários. }\end{array}$ \\
\hline $\begin{array}{l}\text { Rádio telescópio: } 500 \text { metros de abertura } \\
\text { esférica }\end{array}$ & Maior abertura de um radiotelescópio do mundo (2017). \\
\hline $\begin{array}{l}\text { Detector de dark-matter } \\
\text { Detector de neutrinos Daya Bay }\end{array}$ & Pandax: maior laboratório subterrâneo do mundo. \\
\hline
\end{tabular}

Fonte: Adaptado de Van Noorden (2016).

O Quadro 1 fornece uma amostra das pretensões e disposição chinesas de transformar o país em uma potência de primeira linha em CT\&I, como transparece no pronunciamento do presidente da China e secretário geral do Partido Comunista, Xi Jinping, ao explicitar os objetivos de "fazer da China um dos países mais inovadores do mundo em 2020, uma liderança maior em inovação em 2030 e, finalmente, tornar a China uma potência mundial em c\&T no aniversário de cem anos de fundação da República Popular, em 2049"5.

Desde os anos de 1980, a China investe volumes crescentes na criação e no fortalecimento de instituições de pesquisa. Mas foi na década de 1990, e sobretudo nos anos 2000, que o governo passou a se dedicar com mais vigor à tecnologia e à inovação como meios de impulsionar o crescimento econômico (Springut, Schlaikjer e Chen, 2011). A partir desse período, o governo definiu diretrizes, priorizou segmentos estratégicos e estabeleceu metas para transformar a China na maior potência tecnológica global na segunda metade do século Xxi. Trata-se de uma estratégia de longo prazo, com o objetivo de mudar radicalmente a situação do país em um intervalo de cinquenta anos.

na lua em 1969, e o complexo European Organization for Nuclear Research (Cern, de 1954), que se utiliza dos maiores e mais avançados instrumentos de prospecção da estrutura básica da matéria (como o acelerador de partículas The Large Hadron Collider, de 2008). Ver Qiu (2016) e Hiltzik (2015).

5. "China should establish itself as one of the most innovative countries by 2020 and as a leading innovator by 2030, finally becoming a world s\&T power by the 100th anniversary of the founding of the People's Republic of China in 2049." ("President Xi's speech on science, technology”, 2016, tradução livre). 
GRÁFICO 2

Dispêndios em PƯD, em Preços Correntes - Principais Países (em milhöes de US\$PPP)

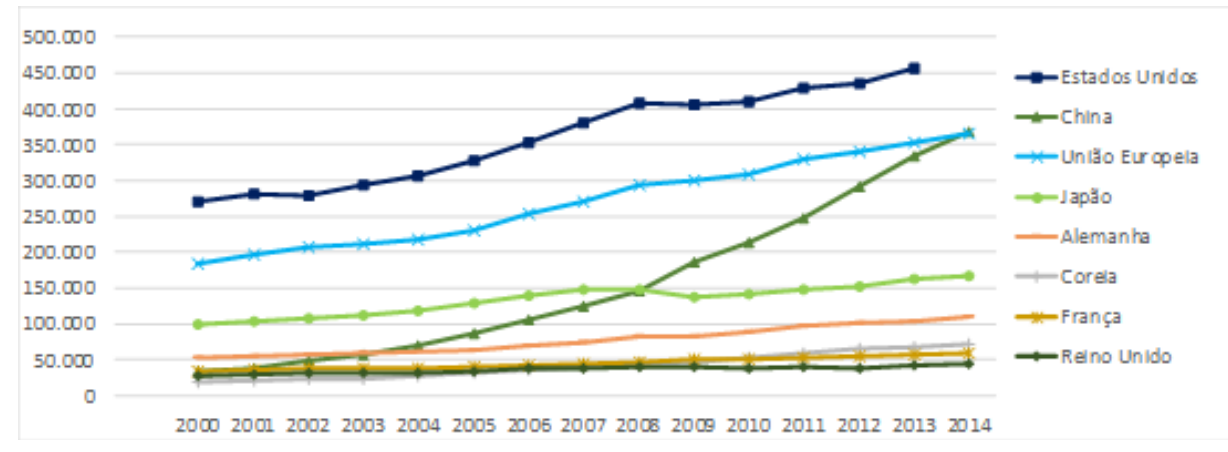

Fonte: OECD, 2016 (http://stats.oecd.org/\#). Dados acessados em 12 de março de 2018.

As iniciativas do governo chinês já deram frutos, tanto na elevação dos indicadores de CT\&I quanto na construção de grandes corporações que competem agressivamente no mercado internacional. Por exemplo, a China se tornou o segundo país que mais investe em P\&D, segundo dados da Organização para a Cooperação e o Desenvolvimento Econômico (OECD).

Em números absolutos, o volume investido quadriplicou em dez anos, de us $\$ 86$ bilhões (2005) para Us $\$ 369$ bilhões (2014). Esse aumento permitiu que a China superasse, em volume de recursos investidos, líderes como Alemanha, França e Japão, passando a responder por cerca de $20 \%$ do investimento global. Mantido o ritmo atual, estima-se que em dois anos o país será líder mundial em dispêndios de P\&D. No mesmo intervalo de dez anos, a China multiplicou por dez as patentes relacionadas às tecnologias de informação e comunicação (TICs) registradas no sistema internacional do Tratado de Cooperação de Patentes (РCT), de acordo com a OCDE (2017).

Em relação ao esforço de formação de profissionais, o número de matriculados no ensino superior praticamente triplicou e o número de pesquisadores na pós-graduação dobrou entre 2003 e 2013. Em 2014, considerando o conjunto de 10\% dos artigos mais citados no mundo, $10 \%$ eram chineses, um índice muito próximo ao dos países da OCDE $(11,2 \%)$.

QUADRO 2

Indicadores Diversos, China

\begin{tabular}{lccc}
\hline INDICADOR & 2005 & 2010 & 2015 \\
\hline Patentes em TICs & 1.813 & 7.200 & 18.444 \\
Pessoal em P\&D & 1.364 .799 & 2.882 .903 & 3.758 .848 \\
Pessoal em P\&D com Nível Superior & 227.163 & 299.296 & 354.861 \\
\hline
\end{tabular}

Fonte: OECD (2017). 
A China trabalha aceleradamente para consolidar um sistema de apoio à inovação sofisticado e orientado para resultados (mission oriented). O tratamento recebido pela indústria é exemplar dessa diretriz, seja pela necessidade de acompanhar as principais tendências tecnológicas, seja por conta do lugar ocupado pela China como a maior produtora mundial de bens de segunda geração, com base em tecnologias maduras. Mais recentemente, os planos do Estado para a indústria ganharam substância com o anúncio do programa Made in China 2025 (MiC 2025) para a indústria avançada.

\section{Foco em inovação e resultados de longo prazo}

A gama de políticas que a China mobiliza para desenvolver tecnologias avançadas é ampla e diversificada. O governo opera com planos quinquenais, que definem objetivos, prioridades, metas, instrumentos, investimentos e critérios de avaliação. Atualmente a China implementa seu $13^{\circ}$ Plano Quinquenal ${ }^{6}$, elaborado para o período de 2016 a 2020, e que definiu as seguintes prioridades:

- Inovação como estratégia para se alcançar o desenvolvimento econômico e social. - Apoio ao desenvolvimento da manufatura avançada.

- Foco nas indústrias emergentes, dentre as quais biotecnologia, indústria de baixo carbono, tecnologias da informação e novos materiais; e nas estratégicas, como aeroespacial, nuclear e ciências da vida.

Além do Plano Quinquenal, o país possui o Programa de Médio e Longo Prazo para o Desenvolvimento da C\&T 2006-2020 (MLP 2006-2020), que tem um horizonte de quinze anos e abrange três Planos Quinquenais.

O MLP 2006-2020 é um marco no processo de construção de uma agenda política pró-inovação na China. Muitas metas quantitativas elaboradas em 2005 para o ano de 2020 continuam vigentes ainda hoje, como:

- Perseguir meta de 2,5\% do PIB investidos em P\&D.

- Elevar para mais de 60\% a contribuição das tecnologias avançadas para o crescimento econômico.

- Limitar em até 30\% a dependência da China de tecnologias importadas;

- Despontar entre os cinco maiores países em depósito de patentes de residentes.

- Assegurar que a produção científica chinesa esteja entre as mais citadas no mundo (ver Unesco, 2015).

6. O $1^{\circ}$ Plano quinquenal foi implementado após a revolução comunista (1953-1957). 
As tecnologias ligadas à manufatura avançada foram elencadas entre as tecnologias de fronteira prioritárias no MLP e compreendem:

- Extreme manufacturing technologies: componentes ou sistemas com tecnologias de escala nanométrica e de alta precisão.

- Intelligent service robot: equipamentos inteligentes operados de forma integrada a outras tecnologias.

- Service life prediction technology: tecnologias de prototipagem e simulação para melhorar controle, confiabilidade e segurança (ver State Council, 2006).

Objetivos tão ambiciosos são sustentados por políticas duradouras, distantes das descontinuidades que atormentam grande parte dos pesquisadores e empresas de países emergentes ${ }^{7}$.

Na esteira do MLP 2006-2020, o governo chinês ampliou suas iniciativas em direção à manufatura avançada com o plano Made in China 2025 (MiC 2025), lançado em 2015. O plano procura responder aos desafios domésticos e preparar a China para as novas indústrias que se desenvolvem no plano internacional.

Do ponto de vista dos desafios domésticos, o MiC 2025 procura combater a ineficiência das empresas industriais chinesas e os efeitos da elevação dos salários e da apreciação da moeda no país, que corroem parte da competitividade da economia

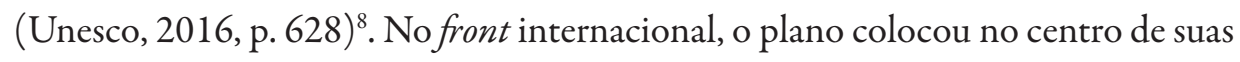
preocupações a digitalização e a automação, que prometem profundas mudanças na manufatura, conforme anunciadas na Alemanha com a plataforma Industrie 4.0.

Para realizar esses objetivos foram definidas cinco diretrizes:

1. Promover a inovação, motor do desenvolvimento.

2. Melhorar a qualidade dos produtos e serviços disponíveis no mercado.

3. Tornar a economia mais sustentável.

4. Otimizar a estrutura industrial.

5. Incentivar a formação e a qualificação dos recursos humanos e a retenção de talentos.

7. Do ponto de vista da estabilidade do financiamento da CT\&I, as diferenças em relação ao Brasil são marcantes e pedem reflexão sobre as dificuldades que o país enfrenta para definir prioridades e metas de médio e longo prazo capazes de otimizar o investimento.

8. Estima-se que os custos de produção na China tenham saltado de $25 \%$ para $40 \%$, comparados aos custos dos Estados Unidos (Delloite e Council on Competitiveness, 2015). Esse aumento permitiu que outros países, a exemplo de Vietnã, Laos e Camboja, se tornassem uma alternativa para a fabricação de produtos de menor valor agregado, como têxteis, vestuário e montagem de eletrônicos. 
No rol das ações estratégicas, dez segmentos foram elencados como prioritários para viabilizar o reposicionamento global da economia chinesa. Compreendem tanto tecnologias de caráter transversal (tecnologias de informação e comunicação), quanto áreas importantes para o desenvolvimento social (meios de transporte, energia, saúde e agricultura).

\section{Investimento externo direto chinês, fusões e aquisições}

Para avançar nessas prioridades, o governo central se articulou com grandes empresas, definiu e concentrou recursos em áreas estratégicas, fez uso intensivo de compras públicas e viabilizou fusões ou aquisições de empresas estrangeiras por conta de tecnologia (European Chamber, 2017).

O investimento direto externo (IDE) da China cresceu cerca de $30 \%$ ao ano entre 2005 e 2015, quando as empresas chinesas passaram a comprar marcas consolidadas globalmente. Os números são expressivos: em 2008, o investimento externo chinês foi de us $\$ 40$ bilhões, ou cerca de 2\% do total mundial; em 2015, us $\$ 140$ bilhões; e em 2016, mais de us $\$ 180$ bilhões, o equivalente a $11 \%$ do total global (Hanemann e Huotari, 2016).

A evolução do investimento externo foi consistente e pode ser subdividida em quatro fases:

- Primeira fase: a internacionalização priorizou o estabelecimento de canais de vendas no exterior.

- Segunda fase: as estatais chinesas se concentraram na aquisição de produtoras de commodities (como óleo e gás) e de infraestrutura.

- Terceira fase: as companhias privadas começaram a se instalar no exterior e/ou a adquirir empresas estrangeiras, como a Lenovo, que comprou parte da operação da IBM, e a Geely, que comprou a Volvo.

- Quarta fase: as grandes empresas privadas tornaram-se o eixo central da estratégia de internacionalização, com o objetivo de ganhar posições nas cadeias globais de valor.

Segundo o Conselho de Estado chinês, a última fase de fusões e aquisições reflete o maior dinamismo das empresas chinesas ${ }^{9}$, que fixaram o continente europeu como alvo especial. A voracidade da China registrou um salto de quarenta aquisições, em

9. A partir do $10^{\circ}$ Plano Quinquenal, o governo chinês trabalhou com a estratégia Going Out, Bringing In para apoiar o investimento das empresas no exterior e atrair grandes corporações, visando à construção de marcas nacionais e à internalização e à transferência de tecnologias. 
2006, para 183, em 2015 (Ernst e Young, 2016) ${ }^{10}$. A Tabela 1 traz alguns exemplos de aquisições recentes realizadas por empresas do país asiático.

TABELA 1

Aquisições e Investimentos Chineses na Europa - 2016 e 2017

\begin{tabular}{|c|c|c|c|c|}
\hline EMPRESA & Setor & PAÍs & US\$ BILHÕES & INVESTIDOR \\
\hline Syngenta (materiais) & Químico & Suíça & 43 & ChemChina \\
\hline Pirelli (pneus) & Automotivo & Itália & 7,7 & ChemChina \\
\hline Supercell (games) & TICs & Finlândia & 8,6 & Tencent Holdings \\
\hline Global Switch (big data) & & Reino Unido & 2,8 & China Telecom \\
\hline $\begin{array}{l}\text { Skyscanner } \\
\text { (plataforma viagem) }\end{array}$ & & Inglaterra & 1,7 & Ctrip \\
\hline Opera Software & & Noruega & 1,2 & Golden Brick Capital \\
\hline Avolon (aviação) & $\begin{array}{l}\text { Transporte e } \\
\text { infraestrutura }\end{array}$ & Irlanda & 2,6 & HNA \\
\hline Piraeus Port Authority & & Grécia & 0,4 & Cosco \\
\hline EEW Energy (energia) & Energia & Alemanha & 1,6 & Beijing Enterprises \\
\hline Meerwind (eólico) & & Alemanha & 1,8 & China Three Gorges \\
\hline SMCP Group (moda) & Moda & França & 1,5 & Shandong Ruyi Tech \\
\hline Punch PowerTrain & Automotivo & Bélgica & 1,1 & Yinyi Invest \\
\hline TechniSat Automotive & & Alemanha & 0,2 & Ningbo Joyson Electronic \\
\hline $\begin{array}{l}\text { Bio Products Laboratory } \\
\text { (medicamentos) }\end{array}$ & Farmacêutico & Inglaterra & 1,1 & Creat Group \\
\hline Manz AG (sistemas) & Equipamentos & Alemanha & 0,03 & Shanghai Elec \\
\hline
\end{tabular}

Fonte: Imprensa especializada, elaboração dos autores. Preços correntes.

A robótica, uma das tecnologias centrais para a manufatura avançada, recebeu especial atenção no $M i C$ 2025. Sua importância é dupla: diminuir o custo do tra-

10. Os principais alvos têm sido a Alemanha, o Reino Unido e a França. Em 2016, apenas a Alemanha (com 11 bilhões de euros) e o Reino Unido (7,8 bilhões de euros) receberam mais de $50 \%$ dos investimentos chineses na União Europeia (Hanemann e Huotari, 2017). 
balho e fazer frente ao avanço de outras economias nos requisitos de qualidade, produtividade e intensidade tecnológica de seus produtos e processos de fabricação. A China estima produzir em 2020 70\% dos robôs do mundo, em competição direta com tradicionais fabricantes como o Japão, a Alemanha e os Estados Unidos. Para tanto, o país desenvolve aceleradamente sua indústria de semicondutores e sistemas integrados de modo a alcançar um domínio pleno da fabricação de robôs.

O investimento no exterior é instrumento-chave para isso, segundo o Conselho de Estado chinês, que apoia concretamente a compra de empresas estrangeiras como estratégia de expansão e absorção de tecnologias. O controle de mais de $80 \%$ da Kuka pelo Midea Group, no valor de us \$ 5,1 bilhões, foi um dos destaques dessa política ${ }^{11}$. A manufatura avançada está relacionada à digitalização, à conectividade e à automação dos processos produtivos, que por sua vez dependem de robôs industriais flexíveis, como os fabricados pela Kuka ${ }^{12}$. Além disso, a China possui, desde 2013, o maior mercado consumidor de robôs do mundo ${ }^{13}$ : segundo algumas estimativas, $25 \%$ do total de robôs em operação na indústria mundial estão na China; com o avanço da indústria, o mercado chinês sozinho teria condições de absorver até 30\% da produção da Kuka (Prodhan e Preisinger, 2016). Para o governo, essas perspectivas aguçam ainda mais sua disposição de avançar sobre um dos pilares centrais da cadeia da manufatura avançada, como mostram as aquisições efetuadas nos últimos anos ${ }^{14}$.

Ao avançar sobre os segmentos de automação e robótica, o governo chinês procura equacionar um dos gargalos mais importantes para a economia, que é sua baixa eficiência produtiva. Nesse sentido, a política de aquisições facilita o acesso a tecnologias, conhecimentos de gestão e domínio de marcas, que contribuem para a formação de competências e para a consolidação de uma base tecnológica própria, capaz de definir tendências no cenário global.

11. A aquisição da Kuka agitou o governo alemão, que enxergou no lance chinês uma ameaça real para seus projetos relativos à indústria 4.0. A Kuka é líder na criação de fábricas automatizadas; seus robôs estão presentes em empresas como Audi, BMw e Boeing.

12. Entre 2010 e 2015 , a demanda global por robôs aumentou cerca de $16 \%$ ao ano, e as vendas anuais atingiram, em média, cerca de 183 mil unidades, contra 103 mil nos anos de 2004 a 2009 (IFR, 2016). Somente em 2015, foram vendidos 254 mil robôs industriais, mais do que o dobro de 2004.

13. A título de comparação, em 2016, a China adquiriu 68.556 unidades ( $27 \%$ das vendas mundiais), enquanto o Brasil, 1.407 (0,5\%) (IRF, 2016).

14. Apenas para ilustrar: em 2016, o fundo de private equity sino-europeu Agic Capital comprou a Gimatec, fabricante italiana de sensores, posicionadores e pinças elétricas e pneumáticas para robôs; o Agic Capital, juntamente com a China National Chemical Group e o fundo estatal chinês Guoxin International Investment Corp adquiriram a KraussMafei Group, empresa alemã especializada em máquinas e equipamentos para produção e processamento de plásticos e borracha. Em outra operação, a americana Paslim, integradora de robôs de soldagem, sistemas de automação e ferramentas, foi comprada pelo Wanfeng Technology Group, em 2015. 
Essa evolução, porém, está longe de ser trivial e direta, principalmente porque não há um processo one-size-fits-all, que seja eficiente para todo tipo de tecnologia, e muito menos para toda e qualquer empresa. Pesquisas junto a grandes corporações que investem sistematicamente no domínio de tecnologias de ponta mostram que a passagem para o universo high-tech de empresas especializadas em inovações de segunda geração ainda constitui uma espécie de caixa-preta difícil de ser decifrada. Isso significa que as aquisições externas nem sempre produzem os resultados esperados pelas novas empresas controladoras, que passam por enormes dificuldades para ampliar sua capacidade de absorção e, assim, desenvolver mecanismos adequados para a produção de tecnologias mais avançadas. Não há, portanto, qualquer relação linear entre a aquisição de tecnologia e a formação de capacidade de inovação endógena e original (Xu et al., 2014). Na mesma direção, Wang e Lu (2013) analisaram as relações entre exportações, investimento em P\&D, iniciativas locais de financiamento e aquisição de tecnologia e ressaltaram que a combinação de estratégias para viabilizar a absorção de conhecimento e a capacitação para inovação de fronteira é variável, depende do tipo da tecnologia e do ambiente

Como se pode ver, apesar de obstinada, a evolução da China enfrenta obstáculos enormes que, no seu devido tempo, foram superados apenas por um pequeno grupo de países desde a Segunda Guerra Mundial. Exatamente por isso, a trajetória chinesa atrai as atenções do mundo todo, em especial dos países emergentes que se esforçam para elevar seu padrão de desenvolvimento.

\section{A plataforma alemã Industrie 4.0}

A plataforma Industrie 4.0, adotada pelo governo alemão em 2015, foi pioneira no esforço de criação e configuração de um novo paradigma industrial e, por isso mesmo, tornou-se referência para países avançados que procuram não perder seu espaço de atuação e sua competitividade, assim como para emergentes que ambicionam disputar um lugar proeminente na arena internacional, como a China.

O termo industrie 4.0 faz referência à quarta revolução industrial atualmente em curso (segundo seus idealizadores), caracterizada pela aplicação intensiva de tecnologias da comunicação e da informação na indústria, com expectativas de disseminação de seu uso em sistemas chamados de cyber-físicos, voltados para a produção de bens e serviços. A evolução tecnológica em andamento prenuncia enormes impactos na competitividade industrial e aponta para uma reconfiguração de toda a indústria, com uma integração intensa com o universo dos serviços, via digitalização, e com os processos de automação avançada (Kagermann et al., 2011). 
A comparação entre o $\mathrm{MiC} 2025$ e a plataforma Industrie $4.0^{15}$ ajuda a compreender a real dimensão dos obstáculos e desafios que as empresas, o Estado e a sociedade chinesa têm pela frente.

A plataforma Industrie 4.0 ocupa lugar central na atual política industrial e tecnológica da Alemanha. Três características principais dessa plataforma têm chamado a atenção dos mais diferentes governos, empresas e pesquisadores: (1) seu foco temático, que se concentra no desenvolvimento de tecnologias de manufatura avançada disruptivas; (2) o horizonte de médio e longo prazo; e (3) a natureza agregadora e a amplitude institucional, aberta à participação de representantes da iniciativa privada, academia, sindicatos de trabalhadores e outras instituições. A mobilização social alcançada pela Industrie 4.0 foi resultado de enorme esforço institucional de construção de consensos, que se originou na iniciativa privada, e se prolongou do seu anúncio na Feira de Hannover em 2011 até sua adoção pelo governo alemão em 2015 como uma plataforma de convergência e de cooperação em defesa da competitividade da indústria alemã ${ }^{16}$.

Apesar de ter sido criada como uma iniciativa propriamente alemã - com o objetivo de elevar a competitividade da indústria e ampliar seu potencial exportador de bens de alto valor agregado -, por seus propósitos e pela linha de futuro que abriu para todas as economias e sociedades, a Industrie 4.0 projetou-se como fonte de inspiração para a criação de programas análogos em países como os Estados Unidos, o Japão, a França, o Reino Unido e a China.

Somente em 2015 a Industrie 4.0 seria incluída oficialmente, e com destaque, nos programas oficiais de governo, graças à intensa movimentação de empresários, empresas, universidades, centros de pesquisa e associações de classe. Por conta dessa origem, seu desburocratizado sistema de governança transformou-se em um de seus pontos distintivos, precisamente por estimular o diálogo e contemplar a diversidade da sociedade civil.

Após sua consolidação como política oficial de governo, a Industrie 4.0 passou a ocupar posição central nos planos da Alemanha e foi integrada à política de inovação mais importante do governo, a Die Neue Hightech-Strategie (A Nova Estratégia High-Tech, relançada em 2014) ${ }^{17}$, e à Digitale Strategie 2025 (Estratégia Digital 2025) ${ }^{18}$.

15. As características básicas das iniciativas e diretrizes da plataforma Industrie 4.0 foram extraídas de Arbix, G. et al. (2017).

16. Em abril de 2013, a Academia Alemã de Ciências e Engenharia (Acatech - Deutsche Akademie der Technikwissenschaften ou National Academy of Science and Engineering) divulgou documento para a implantação da iniciativa Industrie 4.0, que estabeleceu os primeiros focos de ação, ajudou a formar consenso e alinhar atores em torno da relevância da iniciativa para a economia alemã (Kagermann, et al., 2013).

17. Ver Federal Ministry of Education and Research (2014).

18. Ver Bundesministerium für Wirtschaft und Energie, 2016. 
A Nova Estratégia High-Tech, matriz da política industrial alemã, definiu dez projetos para o futuro e incluiu a plataforma Industrie $4.0^{19}$ entre suas prioridades:

- Cidades com eficiência energética e balanço neutro em emissões de $\mathrm{CO}_{2}$.

- Biomassa como alternativa ao petróleo.

- Conversão inteligente de fontes de energia.

- Tratamentos médicos personalizados.

- Saúde preventiva e alimentação.

- Envelhecimento e vida independente.

- Mobilidade sustentável.

- Internet para a economia.

- Industrie 4.0.

- Identificação segura.

Essas políticas procuram acelerar a transferência de conhecimento científico para produtos, processos e serviços e aperfeiçoar o ambiente de inovação $0^{20}$ com o objetivo de manter a Alemanha na liderança mundial em inovação industrial ${ }^{21}$.

Após o reconhecimento oficial do governo alemão, a liderança do programa passou a ser exercida diretamente por dois ministros de Estado (da Educação e Pesquisa e da Economia e Energia), que compartilham sua gestão e coordenação com representantes da iniciativa privada, com membros da academia, de sindicatos e outras entidades. A participação ativa desses atores tem como resultado um alto grau de coesão e de efetividade na formulação, adequação dos instrumentos e na execução da política industrial. Vários entrevistados, inclusive planejadores públicos, afirmaram que a presença do governo na plataforma se dá mais pelo seu papel de facilitador do diálogo e articulador de atores sociais do que como gestor, uma vez que as ações da plataforma são sempre definidas segundo o estilo bottom-up.

Dentre as iniciativas concretas, destaca-se o incentivo à instalação de espaços de teste e de demonstração de tecnologias em sua fase pré-competitiva, chamados de Testumgebungen (em alemão) ou testbeds (em inglês). Esses ambientes de demonstração simulam a realidade da produção industrial e ajudam a consolidar ou a identificar rotas promissoras para novas tecnologias. Podem ser complexos e simular uma fábrica completa, ou bastante simplificados e pragmáticos e assim ser implantados em bancadas de testes ou em máquinas específicas em laboratórios.

19. Ver Bundesministerium für Bildung und Forschung, s/d.

20. Ver Federal Ministry for Economic Affairs and Energy, 2014.

21. "Plattform Industrie 4.0's primary objective is to secure and develop Germany's top international position in industrial manufacturing" (Federal Ministry for Economic Affairs and Energy, 2018). 
Tipicamente, estão instalados em universidades ou centros de pesquisa como infraestrutura compartilhada ${ }^{22}$. A premissa é que as demonstrações em testbeds têm um papel relevante na construção de consensos sobre tecnologias e, especialmente, na formação das visões de futuro, o que contribui para a articulação e a disseminação de informações, definição de padrões, protocolos e métricas das novas técnicas. Essas instalações demonstradoras funcionam também como recurso efetivo para a formação de operadores dos sistemas de manufatura avançada ${ }^{23}$.

Em pouco tempo, os horizontes abertos pela Industrie 4.0 sacudiram o mundo da indústria, ganharam espaço na mídia e envolveram uma ampla gama de empreendedores, empresas, pesquisadores, instituições e governos, inclusive o da China.

\section{MiC 2025 e o Industrie 4.0}

Com base na análise dos princípios norteadores dos planos da China e da Alemanha, e com apoio de informações colhidas em documentos e entrevistas com atores qualificados, assim como na pesquisa de campo realizada na Alemanha, foi elaborado o Quadro 2.

A síntese do que China e Alemanha fazem de modo semelhante pode ser visualizada no Quadro 3.

Apesar de diretrizes gerais coincidentes, os contrastes entre os programas são significativos e expressam, de fato, um desnível entre as políticas dos dois países e, mais importante, o grau diferenciado de maturidade em que se encontram os dois sistemas de inovação e produtivos.

Buscaremos, assim, cotejar os direcionadores do MiC 2025, voltados para preparar o trânsito do made in China para o designed in China, com o que identificamos como lacunas e gargalos à evolução chinesa. A pergunta que orienta essa parte final do artigo tratará, portanto, das barreiras que se apresentam no caminho da China para que deixe sua posição relativa de produtor de "inovações secundárias", ainda que avançadas (Wu, Ma e Xu, 2009), e migre para a de um centro gerador de inovações integradas, originais e desenvolvidas endogenamente.

Nesse sentido, alguns contrastes apresentados no Quadro 2 sugerem a existência de um hiato nada desprezível entre a China e a Alemanha em termos de desenvol-

22. O financiamento das plataformas está em grande parte baseado em mecanismos já existentes e de fácil acesso, como recursos oriundos de fontes controladas por ministérios e outros órgãos públicos, da iniciativa privada e de instituições envolvidas com pesquisa e desenvolvimento tecnológico, como as universidades e o sistema Fraunhofer.

23. Em novembro de 2016, somente na Alemanha foram contabilizados 33 testbeds e 267 espaços de experimentação em empresas. 
QUADRO 2

Sintese do MiC 2025 e Industrie 4.0

\begin{tabular}{|c|c|c|}
\hline Made in China 2025 & Plataforma Industrie 4.0 & \\
\hline Lançamento & • 2015 & $\begin{array}{l}\text { - 2013: entrou em operação coordenada por três asso- } \\
\text { ciações de classe, que haviam anunciado a Plataforma } \\
\text { em 2011, na Feira de Hannover (a associação de } \\
\text { máquinas e equipamentos, VDMA, a de eletrônica, } \\
\text { zVEI, a de tecnologia da informação, comunicação } \\
\text { e mídia, Bitkom. } \\
\text { - Em } 2015 \text { seria relançada como política industrial do } \\
\text { governo alemão. }\end{array}$ \\
\hline
\end{tabular}

\begin{tabular}{|c|c|c|}
\hline Objetivos & $\begin{array}{l}\text { - Elevar o patamar da indústria. } \\
\text { - Transitar do atual "made in China" para o } \\
\text { "designed in China". } \\
\text { - Promover inovação original. } \\
\text { - Tornar a economia mais competitiva e } \\
\text { sustentável. } \\
\text { - Formar e qualificar recursos humanos. } \\
\text { - Reter talentos. }\end{array}$ & $\begin{array}{l}\text { - Avançar na quarta revolução industrial para garantir } \\
\text { posição de vanguarda da indústria. } \\
\text { - Desenvolver aplicação intensiva de tecnologias } \\
\text { digitais, de comunicação e informação na indústria. } \\
\text { - Estruturar sistemas cyber-físicos. } \\
\text { - Enfatizar ambientes de testes. } \\
\text { - Apoiar PME (Pequenas e Médias Empresas). } \\
\text { - Qualificar trabalhadores }\end{array}$ \\
\hline $\begin{array}{l}\text { Referência } \\
\text { internacional }\end{array}$ & - Industrie 4.0, Alemanha. & $\begin{array}{l}\text { - A própria Alemanha. } \\
\text { - Melhores práticas industriais dos Estados Unidos } \\
\text { e Japão. }\end{array}$ \\
\hline Estilo de Operação & $\begin{array}{l}\text { - Top down. } \\
\text { - Sistema de decisão e execução dirigido pelo } \\
\text { governo. }\end{array}$ & $\begin{array}{l}\text { - Bottom Up. } \\
\text { - Sistema de construção de consensos. } \\
\text { - Private sector driven. }\end{array}$ \\
\hline Governança & $\begin{array}{l}\text { - Conselho de Estado. } \\
\text { - National Development and Reform Com- } \\
\text { mission (NDRC). } \\
\text { - Ministério da Ciência e Tecnologia. } \\
\text { - Ministério da Indústria e Tecnologia da } \\
\text { Informação. }\end{array}$ & $\begin{array}{l}\text { - Governo central, estados, empresas, sindicatos, } \\
\text { comunidade científica. } \\
\text { - Dois ministros presidem a plataforma. } \\
\text { - Governo é facilitador. } \\
\text { - Execução a cargo do Steering Body, com trinta repre- } \\
\text { sentantes de empresas. }\end{array}$ \\
\hline Instituições/líderes & $\begin{array}{l}\text { - Conselho de Estado. } \\
\text { - Comissão Nacional de Reforma e Desenvol- } \\
\text { vimento (NDRC). } \\
\text { - Ministério da Ciência e Tecnologia. } \\
\text { - Ministério da Indústria e Tecnologia da } \\
\text { Informação. }\end{array}$ & $\begin{array}{l}\text { - Ministério da Economia e Energia. } \\
\text { - Ministério da Educação e Pesquisa. } \\
\text { - Associação dos Engenheiros da Alemanha (secretaria } \\
\text { geral). } \\
\text { - Associações da indústria. } \\
\text { - Institutos Fraunhofer e Universidades. }\end{array}$ \\
\hline $\begin{array}{l}\text { Posição relativa } \\
\text { do país }\end{array}$ & $\begin{array}{l}\text { - China quer entrar na indústria } 4.0 \text {. } \\
\text { - Precisa aumentar a qualidade, eficiência e } \\
\text { nível de automação. } \\
\text { - Quer inovar mais e melhor para assumir } \\
\text { liderança mundial. }\end{array}$ & $\begin{array}{l}\text { - Alemanha visa a avançar e a manter sua liderança } \\
\text { em manufatura. } \\
\text { - Quer elevar ainda mais a produtividade de sua eco- } \\
\text { nomia e de seus trabalhadores. }\end{array}$ \\
\hline Setores-alvo & $\begin{array}{l}\text { - Estratégia horizontal voltada para setores } \\
\text { tradicionais e avançados. }\end{array}$ & $\begin{array}{l}\text { - Processos produtivos, automação, sistemas, máquinas } \\
\text { e equipamentos. }\end{array}$ \\
\hline Estágio da inovação & $\begin{array}{l}\text { - Imitação. } \\
\text { • Inovação de segunda geração. }\end{array}$ & • Inovação com base em P\&D de primeira geração. \\
\hline Venture Capital & - Mercado de vc em desenvolvimento. & - Mercado de vc maduro. \\
\hline $\begin{array}{l}\text { Propriedade } \\
\text { intelectual }\end{array}$ & • Proteção ainda insuficiente. & - Proteção efetiva. \\
\hline
\end{tabular}




\begin{tabular}{|c|c|c|}
\hline Made in China 2025 & Plataforma Industrie 4.0 & \\
\hline $\begin{array}{l}\text { Tecnologias } \\
\text { prioritárias }\end{array}$ & $\begin{array}{l}\text { - Tecnologias da informação. } \\
\text { - Máquinas CNC e automação. } \\
\text { - Aeroespacial e aeronáutico. } \\
\text { - Equipamentos marítimos. } \\
\text { - Transporte ferroviário. } \\
\text { - Veículos de energia limpa. } \\
\text { - Equipamentos elétricos. } \\
\text { - Novos materiais. } \\
\text { - Biomedicina. } \\
\text { - Equipamentos agrícolas. }\end{array}$ & $\begin{array}{l}\text { - Internet das coisas. } \\
\text { - Sensores. } \\
\text { - Robôs industriais. } \\
\text { - Impressão 3D. } \\
\text { - Big data. } \\
\text { - Analytics. } \\
\text { - Sistemas Integradores. } \\
\text { - Computação em nuvem. } \\
\text { - Mobile internet. } \\
\text { - Segurança cibernética. }\end{array}$ \\
\hline Duração & - Dez anos. Novas fases: 2035 e 2049. & - Indefinido. \\
\hline Internacionalização & $\begin{array}{l}\text { - Plano agressivo de aquisição de empresas } \\
\text { estrangeiras de tecnologia. }\end{array}$ & $\begin{array}{l}\text { - Foco em exportação. } \\
\text { - Empresas alemãs são objeto de cobiça, em especial do } \\
\text { investimento externo chinês. }\end{array}$ \\
\hline
\end{tabular}

Fonte: Elaboração dos autores com base em: Bundesministerium für Wirtschaft und Energie (2016), State Council (2015) e Federal Ministry for Economic Affairs and Energy (2014).

QUADRO 3

O que Há de Comum nos Programas da Alemanha e China

Priorizam tecnologias digitais.

Mantêm foco em automação avançada e robótica cooperativa.

Abrem caminho para indústrias emergentes (IoT, Bigdata, 3D Printing...).

Apoiam a internacionalização de empresas e de instituições de CT\&I.

Utilizam sistemas de compras públicas.

Implementam projetos de alto impacto econômico, tecnológico e social.

Buscam produção mais limpa e sustentável.

Criam novos Fundos de vc e de apoio a startups de tecnologia.

Fonte: Elaboração dos autores.

vimento tecnológico e do patamar distinto em que os países se encontram, como se pode ver por meio de três dimensões constitutivas de um sistema de inovação de qualidade: (1) o ambiente de inovação; (2) o esforço de P\&D; e (3) a natureza dos processos de decisão.

\section{0 ambiente de inovação e os entraves à P\&D}

Um dos maiores desafios que países em desenvolvimento enfrentam é exatamente o de escalar seu processo de catching up de modo a elevar o patamar de desenvolvimento 
e bem-estar de sua economia e sociedade. Nos estágios iniciais, o investimento em capital físico, construção, indústria pesada e em infraestrutura desempenha papel de primeira grandeza e viabiliza a enorme migração do campo para as regiões urbanas, ou seja, de atividades com baixa produtividade para setores mais dinâmicos. À medida que vão sendo vencidas essas etapas iniciais, esse padrão tende a se esgotar e seus impactos transformadores começam a diminuir.

A China emite sinais de que incorporou algumas experiências de desenvolvimento ${ }^{24}$ ao priorizar o investimento em educação e em CT\&I. Mas, conforme a história mostra, é preciso mais do que o investimento.

Instituições importam (Eichengreen, Park e Shin, 2012; Rodrik, 2013). Educação também (Acemoğlu e Robinson, 2016). Assim como a capacitação tecnológica das empresas, que define as dinâmicas da inovação. Mas a combinação dessas dimensões é tarefa complexa, principalmente porque muitas instituições que funcionaram bem durante as diferentes fases do processo de catching up deixam de funcionar na transição para economias high-techs e, muitas vezes, transformam-se em obstáculos, como a governança centralizada no Estado, a preferência exacerbada pelas grandes corporações e a grande dependência do investimento público. Breznitz e Murphree apontaram que o "maior risco para o desenvolvimento da China é a interferência do governo central e seu excessivo foco na inovação nacional de alta tecnologia. $O$ fracasso da imposição de um padrão de rede doméstica para certificação e infraestrutura em meados dos anos 2000 continua como um alerta sobre os prejuízos da ultracentralização, que atrasou por quase uma década os trabalhos para o lançamento dos serviços de comunicação $3 G "$ (2010, p. 25).

A concentração de poder e a atuação centralizada do governo chinês, que foi em grande parte responsável pela velocidade das decisões e políticas realizadas até aqui, podem gerar impasses à medida que a sociedade se diversifica, o tecido produtivo se torna mais heterogêneo, os salários mais altos e a produção de conhecimento mais sofisticada.

Dilemas dessa natureza foram enfrentados pelo Japão e pelos tigres asiáticos (Coreia do Sul, Hong-Kong, Singapura e Taiwan), que em sua fase inicial de desenvolvimento se serviram intensamente de seus respectivos Estados e governos, na maior parte de perfil autoritário (Amsden, 1989; Beeson, 2009), para realizarem o catch up. Sua ascensão foi responsável por uma nova onda de estudos com foco nas relações entre inovação e desenvolvimento econômico, capacidade de absorção, aprendizagem e as responsabilidades do setor público.

24. Em especial as experiências bem-sucedidas do Japão e da Coreia, assim como as de países como o Brasil, Argentina e México. 
Uma das lições aprendidas com esses estudos é que as organizações e instituições instaladas nos países emergentes, apesar de formalmente semelhantes às dos países avançados, atuam de modo muito distinto do sugerido pelas teorias tradicionais. Em países como a China (e também o Brasil), as normas, padrões e regras típicas dos sistemas burocráticos de inspiração weberiana não funcionam adequadamente (Breznitz, 2014). A autonomia das regiões chinesas e dos governos provinciais e comunais oferece um contraponto à coordenação do Estado chinês (Rodríguez-Pose e Wilkie, 2016). Características como regularidade, padronização e mesmo impessoalidade fazem parte de suas missões, mas são entrelaçadas por uma malha informal que está na base das múltiplas interpretações da lei e das regras, do modo de execução, de uso dos recursos, das contratações e da influência cultural e política.

As sociedades, as instituições e os países procuram sempre novos caminhos para romper os obstáculos que travam seu bem-estar. A China conseguiu diferenciar suas dinâmicas regionais e provinciais por meio de um esforço de sobrevivência. De modo semelhante, muitas cidades obtiveram sucesso com suas iniciativas, apesar de não terem sido contempladas nas metas do Estado, assim como milhares de empresas que estão distantes dos mecanismos centrais de financiamento mas tiveram êxito em suas empreitadas, mesmo sem subsídios públicos, pois não eram grandes, muito menos estatais. Os exemplos são fartos de cidades chinesas que construíram suas empresas, evoluíram em seus padrões e conseguiram exportar; impulso semelhante levou médias e pequenas empresas a participarem de grandes cadeias de valor, como no setor de comunicações (Tang, Murphree e Breznitz, 2016).

Essa combinação de planejamento e tomada de decisão centralizada com iniciativas que percorrem a sociedade movimentou e movimenta a China de hoje. $\mathrm{O}$ problema é saber até quando.

São vários os estudos que mostram a preferência do governo chinês pelas grandes empresas estatais e mesmo pelas privadas alinhadas aos seus planos estratégicos. Instituições, mecanismos e recursos públicos estão direcionados às áreas e segmentos definidos pelos planos de governo. P\&D em empresas não estatais, embora em geral sejam prioridade do país, não recebem o apoio devido. $\mathrm{O}$ mesmo acontece com pequenas e médias empresas que não conseguem ser selecionadas para integrar consórcios que disputam licitações públicas (Liu et al., 2017).

E isso em circunstâncias em que a capacidade inovadora das empresas chinesas, de forma generalizada, ainda se encontra abaixo da média da Alemanha (ou mesmo do Japão e dos Estados Unidos).

Dados de 2015 indicam que 19,2\% das empresas chinesas com vendas acima de Us\$ 12 milhões a.a. desenvolviam alguma atividade de P\&D. Na indústria de alta tecnologia, a intensidade da P\&D (dispêndio sobre faturamento líquido) foi 
de 2,0\%, ante a média de 2,03\% na União Europeia e da Alemanha com 2,94\%, enquanto a Coreia do Sul registrou 4,23\%, o Japão, 3,29\%, e os Estados Unidos, 2,79\% (Eurostat 2017). Mais ainda, a desagregação dos dados de investimento registra que o número de pesquisadores por mil empregados está apenas um pouco acima do Brasil e muito abaixo da maioria dos países da oCDE. Como expressão de mais uma fragilidade de fundo, apenas $5 \%$ do investimento agregado em P\&D está relacionado à pesquisa básica, contra $18 \%$ nos Estados Unidos e $12 \%$ no Japão (oECD Economic Survey, 2017).

Em outras palavras, é fundamental que todas as energias existentes no país sejam canalizadas para elevar o patamar da economia e da sociedade. A questão de fundo, porém, permanece: a China conseguirá se desfazer de suas amarras, construir instituições adequadas e flexibilizar os canais de comunicação e diálogo entre agentes públicos e privados?

\section{Processos de decisão}

$\mathrm{Na}$ Alemanha, a governança da plataforma Industrie 4.0 é representativa, conta com participação ampla de vários atores, dentre os quais representantes do governo central, dos estados, de empresas, de sindicatos de trabalhadores, da academia e da comunidade científica. O viés é de busca de ganhos para todos os envolvidos por meio do aumento da competitividade e do potencial exportador do país. A liderança exercida pessoalmente por ministros legitima a plataforma e aumenta seu poder de articulação. A representatividade ampla facilita desdobramentos nas várias esferas, como nas ações do sindicato visando à preparação para mudanças na organização do trabalho e na academia visando ao aprimoramento na formação de pessoal.

Diferentemente, o sistema de inovação chinês atua de modo centralizado. É certo que mudou ao longo dos anos, mas carrega as mesmas digitais do Partido Comunista desde o início de suas atividades. As instituições mais importantes que movimentam o sistema dependem de um número reduzido de dirigentes, que definem metas, concebem estratégias, programas, criam instrumentos e implementam suas atividades de modo fiel ao espírito top down (Cao e Suttmeier, 2017).

A principal fonte de poder reside no Conselho de Estado e no grupo dedicado à CT\&I e Educação. Acompanha o Conselho de Estado a NDRC (National Development and Reform Comission), que desenha planos de médio prazo. Um nível abaixo estão o Ministério da Ciência e Tecnologia e o Ministério do Desenvolvimento, que implementam os grandes planos, cuidam do marco legal e regulatório e de seu aprimoramento. Há ainda um terceiro nível, em que atuam as universidades, centros de pesquisa, think tanks e empresas. Esse sistema hierarquizado comanda a 
elaboração e a execução de estratégias de médio e longo prazo e, na maior parte das vezes, com viés pró-empresas estatais.

Alguns analistas, como Bichler e Schmidkonz (2012), chegam a sustentar que a atuação centralizada se tornou ainda mais forte após a crise de 2008, realidade da qual não escapam nem mesmo as universidades. E essa preferência se manifesta apesar do declínio da participação das empresas estatais na composição do PIB. A resultante chama atenção, uma vez que a menor participação no produto chinês é "compensada" por uma presença ainda maior em setores-chave, como na indústria metalúrgica, petroquímica, energia, defesa, finanças, comunicação e transporte. As universidades tampouco são imunes a esse processo decisório centralizado, que pressiona cientistas a adaptarem suas pesquisas às diretrizes de agências de fomento e do governo central, responsáveis pela distribuição e aplicação de recursos públicos (Fu et al., 2013; Liu et al., 2017).

\section{Lições para o Brasil}

A estratégia chinesa é exemplo de atuação pró-ativa de um estado planificador combinada a uma profusão de empreendedorismo, em ambiente próximo do que se conhece como livre mercado. Essa mescla resultou em programas, políticas públicas, novos modelos institucionais e alto investimento concentrado em objetivos definidos centralmente, que estão na base do dinamismo da economia chinesa. Seu atual plano para manufatura avançada, o $\mathrm{MiC} 2025$, inspira-se declaradamente no plano Industrie 4.0 e acompanha os desdobramentos do plano norte-americano intitulado de Advanced Manufacturing Initiative.

Nos ambiciosos planos chineses, as referências e inspirações, diretas e indiretas, às políticas públicas e modelos institucionais de países competidores são frequentes. Inspiração semelhante cabe ao Brasil.

Não se trata de repetir pura e simplesmente políticas desenvolvidas para outras realidades, principalmente se se levam em conta as diferenças estruturais que separam o Brasil da China. O esforço, porém, é o de apreender o movimento que a China realiza para escapar das armadilhas que tornam extraordinariamente difícil a promoção de alterações estruturais que permitem dar seguimento ao desenvolvimento econômico e social. A China aprendeu com o sucesso do Japão e da Coreia, mas também com a estagnação no meio do caminho do Brasil, da Argentina e do México. Não à toa, abriram a economia mantendo o planejamento, e investem pesadamente em educação, ciência, tecnologia e inovação.

O Brasil é um país seguidor em matéria de CT\&I, como era a China há vinte anos. A China avançou e procura o caminho da sua transformação em uma nação 
inovadora. Busca, para isso, diminuir aceleradamente a distância da fronteira do conhecimento produtivamente aplicado.

Nesse sentido, a experiência chinesa - como as práticas mais avançadas sugerem permite realçar pontos importantes para a construção de uma agenda brasileira para CT\&I e, em particular, da elevação do patamar da indústria de transformação. Nesse sentido, sugerimos sete pontos como direcionadores do necessário debate sobre obstáculos e desafios para o Brasil:

- Manufatura avançada deve ser tratada como uma área estratégica pelo governo federal, alvo de ações de médio e de longo prazo.

- Diretrizes devem ser estabelecidas pelo governo federal, com metas claras de áreas em que o país pretende crescer e se destacar no horizonte de cinco, dez até vinte anos, de modo a se distanciar do imediatismo recorrente.

- A definição de prioridades deve partir de desafios ou problemas concretos enfrentados pelo país, de modo que a política seja orientada a resultados (mission oriented approach), diversificando e invertendo, assim, a lógica costumeira de se caracterizar o setor público como receptor de propostas (individuais e/ou institucionais).

- As políticas de CT\&I devem ser articuladas com as de comércio exterior, de meio ambiente e de educação. É fundamental estabelecer diretrizes e alinhar diferentes ministérios, pois sabe-se que há questões regulatórias, de pesquisa, de recursos humanos que afetam diretamente essa agenda.

- É essencial a participação do setor privado na construção da agenda para o país. Isso significa desenvolver o debate sobre os riscos e oportunidades que as transformações tecnológicas atuais abrem para o país. Prioridades nacionais, de médio e longo prazo, não podem ser definidas em gabinetes, mas precisam ser fruto de amplo diálogo na sociedade. Por razões democráticas, mas também pela mudança na natureza dos processos tecnológicos, que dependem da interação e da diversidade para dar conta da complexidade atual. Somente uma coalizão baseada na inteligência, disposição, força empreendedora e capacidade de investimento terá condições de construir uma agenda que favoreça o aumento da produtividade e da competitividade brasileira.

- Para um avanço de qualidade, a ampliação do fluxo de conhecimento, de parcerias internacionais e a aquisição de ativos estratégicos são necessárias. $\mathrm{O}$ apoio à internacionalização das universidades é parte do mesmo esforço para internacionalizar as empresas brasileiras.

- A necessária ampliação do esforço de P\&D nas empresas brasileiras deverá ocupar lugar especial na agenda de futuro. Para isso o Brasil terá de enfrentar e eliminar, ainda que gradativamente, a atuação dos cartórios e do protecionismo que asfixia 
os processos de inovação. Dificilmente haverá renovação no perfil empresarial e ampliação da mobilidade entre empresas, com o surgimento de novos segmentos e indústrias, sem que seja aumentado o grau de competição na economia brasileira. A abertura da economia é essencial para quebrar as amarras da acomodação, herança de anos de uma economia fechada.

\section{Conclusão}

Este artigo procurou levantar os principais aspectos dos planos da China e da Alemanha para a indústria do futuro. Expôs o modo como o governo chinês executa suas estratégias com o objetivo de transformar a China em uma potência mundial em CT\&I. Examinou também os planos e programas alemães, voltados para manter e ampliar a alta competitividade de sua economia, a produtividade de sua força de trabalho e o pioneirismo de sua tecnologia.

Como discutido, há muitos pontos de semelhança entre as estratégias da China e da Alemanha. Mas também há fortes contrastes entre as duas iniciativas, que representam uma excelente oportunidade para aprofundar a discussão sobre a árdua travessia em curso na China, que busca se transformar em um país tecnológica, científica e industrialmente avançado, com uma população de alta renda e qualidade de vida.

De te fabula narratur, disse o poeta ${ }^{25}$. Para o Brasil, e praticamente para todos os emergentes, o debate sobre os esforços chineses, com seus sucessos e fracassos, é fundamental. A China de hoje tem pelo menos duas vantagens. A primeira é realizar seu processo de catching up após a experiência de um pequeno grupo de países que conseguiram se superar e romper as amarras do atraso; a segunda é poder confrontar sua trajetória com as experiências dos países latino-americanos, em especial Argentina, México e Brasil, que ficaram no meio do caminho de seus processos de desenvolvimento. Duas oportunidades para uma reflexão sobre sua própria trajetória.

Os avanços da China constituem vantagem nada desprezível sobre experiências passadas, inclusive sobre o Japão e a Coreia do Sul, seja pelo tamanho de sua economia, pelos recursos que acumulou ou pelo dinamismo de sua sociedade. Essas vantagens, porém, não dão à China passaporte garantido para uma economia puxada pela inovação, como a alemã. Principalmente porque sua institucionalidade é frágil, o executivo é rígido e os mecanismos de governança se pretendem monocraticamente autossuficientes para enfrentar uma jornada repleta de armadilhas.

Mesmo com os extraordinários passos que a China deu e a sua emergência como séria candidata a país movido a inovação, este artigo considerou que, por seus planos,

25. “A fábula fala de você”, de Horácio. 
estratégias e posição relativa no cenário internacional, ainda é um país seguidor e não tecnologicamente desbravador. Seja em termos de pesquisa, de CT\&I ou da capacidade de geração de conhecimento de fronteira, a China tem um longo caminho a percorrer para se transformar efetivamente em um país provedor de tecnologia.

Desde 2015 o Conselho de Estado da China e o Partido Comunista Chinês emitem sinais de mudanças no ambiente institucional, com o reconhecimento da vitalidade das empresas emergentes e de melhorias no sistema de inovação. São acenos promissores pois apontam para práticas econômicas e sociais mais flexíveis e participativas. Espera-se que floresçam.

\section{Referências Bibliográficas}

AcemoĞLu, Daron, \& Robinson, James A. (2016), "Paths to inclusive political institutions”. Disponível em http://scholar-harris.uchicago.edu/sites/default/files/jamesrobinson/files/ path_to_inclusive_political_institutions.pdf, consultado em 12/3/2018.

AmSDEn, Alice H. (1989), Asia's next giant: South Korea and late industrialization. Nova York, Oxford University Press.

ABDI. (2017), Inovação, manufatura avançada e o futuro da indústria: uma contribuição ao debate sobre as politicas de desenvolvimento produtivo. Brasília, ABDI.

Arbix, Glauco et al. (2017), "O Brasil e a nova onda de manufatura avançada: o que aprender com Alemanha, China e Estados Unidos”. Novos Estudos Cebrap, 36 (3): 2949. Disponível em <http://www.scielo.br/scielo.php?script=sci_arttext\&pid=S0101$-33002017000300029 \& \operatorname{lng}=$ en\&nrm=iso $>$, consultado em 8/4/2018.

BEESON, Mark. (2009), "Developmental states in East Asia: a comparison of the Japanese and Chinese experiences”. Asian Perspective, 33 (2): 5-39.

Bichler, Joseph \& Schmidkonz, Christian. (2012), The Chinese indigenous innovation system and its impact on foreign enterprises. Munique, Munich Business School/University of Applied Sciences.

Breznitz, Dan. (2014), “The cardinal sins of innovation policy”. Harvard Business Review. Disponível em https://hbr.org/2014/07/the-cardinal-sins-of-innovation-policy, consultado em 12/3/2018.

Breznitz, Dan. \& Murphree, Michael. (2010), "How China innovates: run of the red queen". China Economic Quarterly.

Breznitz, Dan. \& Murphree, Michael. (2011), Run of the red queen: government, innovation, globalization, and economic growth in China. New Haven, Yale University Press.

Bundesministerium für Bildung und Forschung (s/d). "Zukunftsprojekte der Bundes- 
regierung". Disponível em http://www.hightech-strategie.de/de/Zukunftsprojekte-der-Bundesregierung-972.php, consultado em 12/3/2018.

Bundesministerium für Wirtschaft und Energie. (2016), Digitale strategie 2025. Disponível em https://www.bmwi.de/Redaktion/DE/Publikationen/Digitale-Welt/digitale-strategie-2025.pdf?_blob=publicationFile\&v=18, consultado em 12/3/2018.

CaO, Cong. \& Suttmeier, Richard. P. (2017), "Challenges of s\&t system reform in China”. Science, 355 (6329): 1019-1021.

Delloite \& Council on Competitiveness. (2015), Advanced technologies initiative: manufacturing \& innovation. Disponível em https://www2.deloitte.com/content/dam/Deloitte/us/ Documents/manufacturing/us-indprod-deloitte-and-council-on-competitiveness-advanced-tech-report.pdf, consultado em 16/7/2018.

Eichengreen, Barry; Park, Donghyun \& Shin, Kwanho. (2012), “When fast-growing economies slow down: international evidence and implications for China”. Asian Economic Papers, 11 (1): 42-87. Disponível em https://www.mitpressjournals.org/doi/pdf/10.1162/ ASEP_a_00118, consultado em 16/7/2018.

ERNST \& YOUnG. (2016), Going out: the global dream of a manufacturing power. 2016 China Outbound Investment Outlook. Disponível em https://www.ey.com/Publication/vwLuAssets/ey-2016-china-outbound-investment-outlook-en/\$FILE/ey-2016-china-outbound-investment-outlook-en.pdf, consultado em 16/7/2018.

Eurostat. (2017), "R\&D expenditure in the EU remained stable in 2016 at just over 2\% of GDP". Newsrelease, 183. Disponível em http://ec.europa.eu/eurostat/ documents/2995521/8493770/9-01122017-AP-EN.pdf/94cc03d5-693b-4c1d-b5ca8d32703591e7, consultado em 12/3/2018.

European Chamber. (2017), China manufacturing 2025: putting industrial policy ahead of market forces. China, European Union Chamber of Commerce.

Federal Ministry for Economic Affairs and Energy. (2014), New high-tech strategy: innovations for Germany. Disponível em https://www.bmbf.de/pub/HTs_Broschuere_eng.pdf, consultado em 12/3/2018.

Federal Ministry for Economic Affairs and Energy. What is Industrie 4.0? (2018), Disponível em http://www.plattform-i40.de/I40/Navigation/EN/Industrie40/WhatIsIndustrie40/ what-is-industrie $40 . h t m l$, consultado em 12/3/2018.

Fu, J., Frietsch, R. \& Tagscherer, U. (2013), Publication activity in the Science Citation Index Expanded (Scie) Database in the context of Chinese Science and Technology Policy from 1977 to 2012. Fraunhofer Isi Discussion Papers n. 35.

Hanemann, Thilo \& Huotari, Mikko. (2016), A new record year for Chinese outbound investment in Europe. Berlin, Mercator Institute for China Studies, Merics.

Hiltzik, Michael. (2015), Big science: Ernest Lawrence and the invention that launched the military-industrial complex. Nova York, Simon \& Schuster. 
IFR - International Federation of Robotics. (2016), World robotics. Institute of Scientific and Technical Information of China. Statistics Data of China's Scientific Papers 2017 - Report on China’s Output of High-quality Scientific Papers.

Kagermann, Henning et al. (2011), "Industrie 4.0: Mit dem Internet der Dinge auf dem Weg zur 4 industriellen Revolution”. VDI nachrichten, 13 (2). Disponível em https://www.bmwi. de/Redaktion/DE/Publikationen/Digitale-Welt/digitale-strategie-2025.html, consultado em 12/3/2018.

KAGERMANN, Henning et al. (2013), Recommendations for implementing the strategic initiative Industrie 4.0. Final Report of the Industrie 4.0 Working Group. Berlin, Acatech.

LeE, Keun. (2013), Schumpeterian analysis of economic catch-up. Cambridge, Cambridge University Press.

LiU, Feng-chao et al. (2011), "China's innovation policies: evolution, institutional structure, and trajectory”. Research Policy, 40 (7): 917-931.

LiU, Xielin; Schwaag, Serger; Tagscherer, U. \& Chang, A. Y. (2017), "Beyond catch-up: can a new innovation policy help China overcome the middle income trap?". Science and Public Policy, 44 (5): 656-659.

OECD. (2017), Main science and technology indicators, vol. 1.

OECD. (2016), Science technology and innovation outlook 2016.

OECD. (2017), Economic survey of China 2017. More resilient and inclusive growth. Beijing, 21 March.

"President XI's speech on science, technology”. (2016), China Daily USA, 2 jun.

Prodhan, Georgina \& Preisinger, Irene. (2016), "Kuka's robotics boss sees benefits of Chinese ownership”. Reuters, 22 jun.

QIU, Jane. (2016), “China bets big on big facilities”. Science, 353 (6306): 1353.

Rodríguez-Pose, Andrés \& Wilkie, Callum. (2016), "Putting China in perspective: a comparative exploration of the ascent of the Chinese knowledge economy". Cambridge Journal of Regions, Economy and Society, 9 (3): 479-497.

RoDrik, Dani. (2013), Structural change, fundamentals, and growth: an overview. Disponível em http://j.mp/2nyz4as, consultado em 12/3/2018.

Royal Society. (2011), Knowledge, networks and nations: global scientific collaboration in the 21 st century. Londres, Elsevier.

Springut, Micah; SCHLAIKJER, Stephen \& CHen, David. (2011), China's program for science and technology modernization: implications for American competitiveness. Report prepared for Us-China Economic and Security Review Commission. Disponível em http://sites. utexas.edu/chinaecon/files/2015/06/UsCC_Chinas-Program-for-sT.pdf, consultado em $13 / 3 / 2018$.

State Council the People's Republic of China. (2015), Made in China 2025. Disponível em http://www.cittadellascienza.it/cina/wp-content/uploads/2017/02/IoT-onE-Made-in-China-2025.pdf, consultado em 23/7/2017. 
STATE Council the People's Republic of China. (2016). China continues to support high-tech manufacturing, 26/7/2016. Disponível em http://english.gov.cn/state_council/ministries/2016/07/26/content_281475402061566.htm, consultado em 20/2/2018.

TAng, Li; Murphree, Michael \& Breznitz, Dan. (2016), “Structured uncertainty: a pilot study on innovation in China's mobile phone handset industry". The Journal of Technology Transfer, 41 (5): 1168-1194.

Unesco. (2015), Unesco Science Report: towards 2030. Paris, Unesco Publishing.

Van Noorden, Richard. (2016), "China by the Numbers”. Nature, vol. 534: 452-453. Disponível em https://www.nature.com/polopoly_fs/1.20122!/menu/main/topColumns/ topLeftColumn/pdf/534452a\%20(corrected).pdf, consultado em 16/7/2018.

Xu, Qingrui et al. (2014), "An analysis of the evolution path to and the driving factors of, the independent innovation of enterprises in the transitional economy: a longitudinal case study on haier group from 1984 to 2013". Management World, 4: 14.

WANG, Yongdong \& LU, Liejin. (2013), "Export-oriented economy as moderator of the relationship between technology acquisition model and independent innovation". 6th International Conference on Information Management, Innovation Management and Industrial Engineering (ICIII), 3: 34-37. IEEE.

Wu, Xiabo; MA, Rufei \& Xu, Guannan. (2009), "Accelerating secondary innovation through organizational learning: a case study and theoretical analysis". Industry and Innovation, 16 (4-5).

Zhou, Yu; Lazonick, Willian \& Sun, Yifei (eds.). (2016), China as an innovation nation. Oxford, United Kingdom, Oxford University Press.

\section{Resumo}

Made in China 2025 e Industrie 4.0: a difícil transição chinesa do catching up à economia puxada pela inovação

Este artigo estabelece uma comparação entre os principais planos executados pelo governo chinês para elevar o patamar tecnológico de sua economia e a plataforma Industrie 4.0, patrocinada pelo governo da Alemanha. Referência mundial para países avançados e emergentes, a plataforma Industrie 4.0 prenunciou profundas transformações no universo da manufatura com impactos em todas as sociedades. Os autores indicam que na arena tecnológica, apesar de avanços enormes, a China ainda não alcançou os padrões da Alemanha e de países como os Estados Unidos e o Japão. A efetivação dos ambiciosos planos chineses, em especial do Made in China 2025, tem pela frente desafios institucionais e tecnológicos significativos, como a incerteza estrutural que permeia a economia e as preferências oficiais pelas empresas públicas e grandes corporações privadas, derivadas do estilo top down de decisão que marca a atuação do Estado chinês. Os autores argumentam que a continuidade da progressão chinesa para além do catching up depende de sua capacidade de combinar a busca de tecnologias de ruptura com a construção de um ambiente mais 
flexível, capaz de difundir a inovação e manter o upgrading constante da capacidade endógena de desenvolvimento de CT\&I.

Palavras-chave: China; Alemanha; Manufatura avançada; Tecnologia; Políticas públicas.

\section{Abstract}

Made in China 2025 and Industrie 4.0: the difficult Chinese transition from catching up to an economy driven by innovation

This article compares the main programs implemented by the Chinese government to raise the technology level of its economy and the platform Industrie 4.0, sponsored by the German government. World reference for advanced and emerging countries, the platform Industrie 4.0 is causing profound transformations in the manufacturing universe with impacts across society. The authors argue that China has not yet reached the standards of Germany and countries such as the United States and Japan in the arena of advanced manufacturing technologies. The implementation of ambitious Chinese plans, especially Made in China 2025, face significant institutional and technological challenges, such as the structural uncertainty that permeates the economy, government preference for public enterprises and large private corporations, derived from the top-down style of decision that marks the performance of the Chinese state. The authors emphasize that the continuity of Chinese progression beyond catching up depends on its ability to combine the search for breakthrough technologies with the construction of a more flexible environment, able to diffuse innovation in the economy and maintain the constant upgrading of endogenous capacities of ST\&I development in China.

Keywords: China; Advanced manufacturing; Industrie 4.0; MiC 2025; Industry of the future; Innovation policies.

Texto recebido em 14/3/2018 e aprovado em 21/5/2018.

DOI: 10.11606/0103-2070.ts.2018.144303.

GLAUCO ARBIX é professor titular da USP, coordenador do Observatório da Inovação e Competitividade do Instituto de Estudos Avançados (IEA-USP).E-mail: garbix@usp.br.

ZIL MIRANDA é especialista em desenvolvimento produtivo da Confederação Nacional da Indústria (CNI) e professora do Programa de Pós-graduação da UfABC. E-mail: zilmmiranda@ gmail.com.

DEMÉTRIO TOLEDO é professor doutor do bacharelado em relações internacionais da UFABC. E-mail: demetrio.toledo@ufabc.edu.br.

EDUARDO ZANCUL é professor doutor da USP, pesquisador do Observatório da Inovação e Competitividade do IEA-Usp. E-mail: ezancul@usp.br.

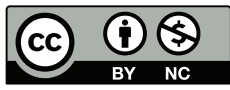

